Nigerian Journal of Technology (NIJOTECH)

Vol. 35, No. 1, January 2016, pp. 54 - $\mathbf{5 9}$ Copyright@ Faculty of Engineering, University of Nigeria, Nsukka, Print ISSN: 0331-8443, Electronic ISSN: 2467-8821

www.nijotech.com

http://dx.doi.org/10.4314/njt.v35i1.9

\title{
PERFORMANCE EVALUATION OF A PILOT PARAPLEGIC CENTRICITY MOBILITY AID
}

\author{
F. I. Ashiedu ${ }^{1}{ }^{*}$, E. O. Popoola ${ }^{2}$ and E. E. Akpan $^{3}$ \\ 1 Dept of Mechanical Engr., Federal University of Petroleum Resources, EFfurun, Delta State. Nigeria \\ 2 Department of Mechanical Engineering, Delta State Polytechnic, OGhara, Delta State. Nigeria \\ 3 DEPARTMENT OF MEChANICAL ENGINEERING, UnIVERSiTy of Uyo, UYo, AKWA IBOM STATE. NIGERIA \\ E-mail addresses: ${ }^{1}$ ashiedu.ifeanyi@fupre.edu.ng, ${ }^{2}$ eunicepeter73@yahoo.com, ${ }^{3}$ memetie@yahoo.com
}

\begin{abstract}
This paper was aimed at evaluating the functional characteristics of a developed mobility aid for paraplegics in Benin City, Nigeria using their anthropometric data. These functional characteristics were compared with the conventional motorised wheel chair found in most city centres in Nigeria under the same condition. The method adopted in establishing the differences in the developed mobility aid and the conventional types include the use of variables such as, the time required to board, time to complete a 100 meters distance, fuel consumption rate and the subjects' operational postural angles. The values obtained from these findings were computed and compared with the values obtained from the conventional wheel chair under the same operational conditions. Consequently, the values obtained were subjected to statistical analysis using the Van der Waerden normal score test and the Wilcoxin's signed rank test. The result of the test showed a remarkable improvement in fuel consumption rate, ease of use and other functional characteristics of the developed mobility aid over the conventional wheelchair available to paraplegics in Nigeria. From the result, it is evidential that the developed mobility aid meets the requirements of adult paraplegics in Nigeria. The use of this mobility aid will make them lead a normal way of life and contribute meaningfully to national growth and development.
\end{abstract}

Keywords:-Paraplegics, Evaluation, Mobility Aids, Wilcoxin's Signed Rank Test

\section{INTRODUCTION}

Certainly, disabled persons in Nigeria are deprived of their fundamental human rights. They find it increasingly difficult to access public places where skills, health services, educational facilities and other social services can be acquired. This act of deprivation is conceived, planned nurtured and executed by Architects, Engineers and Designers who always install stairs and escalators in public buildings instead of the desired ramps, rails, hallways and lifts. Apart from these architectural barriers, the society on their own places social attitudinal barriers in the ways of the disabled, too bad. These barriers are manmade predominantly aimed at disabling the already disabled in the society. Worse still are government budgets at all levels that are close to nothing in improving access of the disabled persons to point of service deliveries. Elsewhere, the disabled in the society are intergraded into all facets of national development through inclusive design strategies. These strategies are aimed at making the disabled persons execute their daily task conveniently, hence leading to assured feelings of self-reliance, increased motivation and high selfesteem.

However, for the disabled to be integrated fully into the society, certain assistive devices such as mobility aids, ramps, kerbs, walkways and lifts that will be economically and ergonomically friendly become imperative. This paper therefore seeks to establish and recommend the most cost effective, ease of use and user friendly motorised wheelchair available to paraplegics in Nigeria using statistical analytical tools. In the light of the above, notable researchers including [1] noted that numbers of the disabled persons in Nigeria are so significant that no serious nation in terms of economic and infrastructural development can afford to toy with. In a related development, [2], [3], and [4] investigated the effects of mobility aids on 
the standard of living of the disabled. The papers also recommended assistive aids for them so as to reduce their dependency on caregivers and family members. In order to guarantee the use of some mobility aids in terms of reliability, availability and ease of use,[5] studied the different components used in the design and development of wheelchairs and recommended materials that provides more adjustability's and movement efficacies of the chairs. A study carried out in Ibadan, a city in western Nigeria by [6] showed that the level of accessibility of wheelchairs to public buildings in Ibadan based on America with Disabilities Accessibility Guidelines (ADAAG) is $19.4 \%$ of the buildings surveyed. Other notable researchers that studied the mobility and accessibility requirements of the disabled in a built up environment include [7], [8] and [9].

Elsewhere,[10]observed with dismay that most developing nations of the world fail to accord priorities to the plight of people with disabilities as against the standard rule of egalitarianism which demands that all countries must ensure that the development, production, distribution and provision of assistive devices for persons with disabilities be given priority in order to increase their rights. Also, [11] noted that eliminating world poverty will not be possible unless the mobility and accessibility needs of the disabled are taken into account.

In a related development, [12] established the desired state of accessibility among community duelling American adults and also advised that all physical barriers limiting the accessibility and mobility of the disabled be removed and be replaced with structures that will support them. In a similar work, [13] examined critically the Nigerian disability policies with a view to ascertaining the actual level of conformity. The paper observed a significant departure from the policies. Elsewhere, [14] studied the accessibility pattern of some public buildings in some selected centres by the disabled in Accra, Ghana. The paper added that while some centres were inclusively built, other centres that housed these public buildings in the same municipality were designed and built without considering the plight of these set of persons.

As part of the requirement to make life more meaningful for the disabled persons in various part of the sphere [15], [16], [17], [18] and [19] at various times researched on the accessibility and mobility requirements of the disabled, their findings showed that different categories of disabled persons require special mobility and accessibility aids. They added that the nature of the built up environment also affects the general mobility pattern of these set of persons. Finally, the aging population was treated as part of the disabled by [20]. The paper added that governments at all levels, nongovernmental organisations, designers and builders must consider the plight of these group of persons at the design stage of all public infrastructures. From literature, it is clear that most developed nations of the world had done much in terms of accessibility and mobility, education and social life of the disabled. Unfortunately, most developing nations of the world like Nigeria fail to accord priority to the plight of people with disabilities. Worse still is the budgetary provision that is near zero. Unless the mobility and accessibility needs of the disabled are met, the world poverty cannot be eliminated [21]. Also, other programmes like the millennium development goals, poverty eradication strategy and other national development initiatives will fail if these set of persons whose number remained significant in our census record are not cared for.

This is the time for Nigeria as a developing country saddled with unemployment problems, inadequate infrastructural facilities, low gross domestic product and serious security challenges among others to adopt affirmative strategies to include people with disabilities in mainstream education, vocational training, political and recreational activities. Government at all levels is urged to as a matter of urgency make available appropriate mobility and other assistive aids to these set of persons so that they can lead a normal life. Again, government must begin to plan for the removal of all architectural and design barriers in public places and buildings thus keying into the inclusive design policy of most developed nations.

The result revealed that paraplegics have no choice but to accept these wheelchairs since they are free gift or given to them at a very convincing discount. Users had to go against the tenets of ergonomics by adapting themselves to the wheelchairs. This may be a pronounced factor responsible for the numerous epidemiological conditions experienced by paraplegics after propulsion [22]. It is therefore important and necessary to use paraplegics' anthropometry in the design concept of wheelchairs and other assistive aids. When this is done, the wheelchair becomes more efficient, provides greater comfort, fit and provide support for users. The use of 
an ergonomically designed wheelchair among others will encourage paraplegics to learn and acquire skills, access education, and health care facilities, attend social functions and participate in sporting activities. Above all, paraplegics will be relatively productive in the larger society.

Ability of paraplegics to participate in all these promotes their self esteem, makes them to be self reliant and contribute meaningfully to the gross domestic product (GDP) of Nigeria. By this, paraplegics will be part of the success story of the millennium development goal of the Federal Republic of Nigeria and the World in general.

\section{RESEARCH METHOD}

Paraplegics with healthy upper functional torso were used to carry out this test. The critical areas of interest used in the work are, the postural angles assumed during operation, the time taken to board and alight under relaxed condition, the fuel consumption rate and the time taken to complete a distance of 100 metres. All these performance attributes were observed and taken and recorded in both the designed monocoque and the conventional mobility aids. The data generated from the study were subjected to Asymptotic Relative efficiency (A.R.E) test. The Asymptotic Relative efficiency test was used because among other statistical methods of comparism (A.R.E) test is the most universally accepted method for comparing and analyzing data.

The Van der waerden's location shift model was used to analyze the data obtained.

If $\mathrm{f}$ is the distribution location corresponding to data obtained from the use of the developed mobility aid (x) and

$\mathrm{G}$ is the distribution function corresponding to data (y) obtained from the normal conventional motorised wheel chair. Then

$\mathrm{G}(\mathrm{t})=\mathrm{F}(\mathrm{t}-\nabla)$

Where $\nabla$ is the amount of location shift between the two set of data

Also,

$\mathrm{YdX}+\nabla=0$

$\mathrm{d}=$ ' has the same distribution even as the test reduces the matched pair $\left(\mathrm{x}_{1}, \mathrm{y}_{1}\right)$ to a single observation by considering the difference $\mathrm{D}$.

$\mathrm{D}_{1}=\mathrm{y}_{1}-\mathrm{x}_{1}$

and $\mathrm{I}=1,2, \ldots \ldots ., \mathrm{n}$

Only non - zero value of $\mathrm{D}$ are valid.
If $\mathrm{R}$ represents signed rank for $\mathrm{D}$ column matrix vector and $A_{1}$ is the signed normal score obtained from normal distribution table, then $A_{1}$ is given by

$$
\mathrm{A} 1=\frac{1}{2}\left[1+\frac{R}{n+1}\right]
$$

And the test statistic is given by

$$
\mathrm{TK} 1=\frac{\sum_{j=1}^{n} A 1}{\sum_{i=1}^{n} A}
$$

The test hypotheses for this analysis are:

$\mathrm{H}_{\mathrm{o}}$ is the Hypothesis that the mobility aid developed is the same with the existing once, $\mathrm{H}_{1}$ is the Hypothesis that the developed mobility aid is different from the conventional mobility aid in use. This was tested at 5 percent level of significance.

\section{RESULTS}

The ergonomic and functional attributes of the mobility aid designed and developed were tested against the conventional motorised wheelchair to ascertain the degree of conformity of the machines to the standard ergonomic principles. The critical aspects of the machine operation tested include examination of the postural angles the disabled especially paraplegics assumed during operations, the time taken to board and alight from the machine, the time taken to complete one hundred metres and the fuel consumption rate. The results of the analysis are as presented below;

\subsection{Testing the Ergonomic and the Functional Attributes of the Developed Mobility Aid}

Table 1 shows the application of Van de Waerden (normal scores), test. Recalling that $\mathrm{T}_{2}$ in equation 5 is given as:

$$
\begin{gathered}
T_{2}=\frac{\sum_{i=1}^{n} A_{1}}{\sum_{i=1}^{n} A_{1}^{2}} \\
T_{1}=\frac{\sum_{i=1}^{n} A_{1}}{\sum_{i=1}^{n} A_{1} \times \sum_{i=1}^{n} A_{1}}=\frac{1}{2.49975}=0.40004
\end{gathered}
$$

Where, $\mathrm{T}_{1}$ is the test statistic.

\subsection{Analysis of the Seating and Postural Support Element}

During testing, it was observed that paraplegics achieved variable positioning using the ergonomic chair designed and developed. This variable positioning achieved at all times during testing was as a result of the adjustability features incorporated in the design. The back test can be preset to various angles as required by paraplegics to aid comfort. Similarly, all reach positions were easily and conveniently attained. However, the comparison 
between the fabricated monocoque seating arrangement and the existing wheelchair seating arrangement is shown in Table 2 .

Similarly, recall that, $\mathrm{T}_{1}$ is the test statistic.

Also important in this comparison is the time $(\mathrm{t})$ taken by the conventional wheel chair type to cover a distance of $100 \mathrm{~m}$ and that taken by the developed monocoque to cover the same distance.
Obtaining the value of $\mathrm{T}_{2}$, we use the corresponding $\mathrm{p}$ value from standard table is $0.6293 . \mathrm{H}_{\mathrm{o}}$ is therefore rejected; the two have different operating characteristics. As a confirmatory test, Wilcoxon's Signed Rank Test for paired differences was employed to confirm the significant differences observed using Van Der Waerden (score test).

Table 1: Application of Van der waerden (normal scores) test

\begin{tabular}{|c|c|c|c|c|c|c|}
\hline $\begin{array}{c}\text { No of } \\
\text { paraplegics }\end{array}$ & $\begin{array}{c}\text { Time taken to board } \\
\text { the existing } \\
\text { wheelchair (sec) }\end{array}$ & $\begin{array}{l}\text { Time taken to board } \\
\text { the monocoque (sec) }\end{array}$ & $\begin{array}{l}\text { Difference } \\
\qquad D_{\mathrm{i}}\end{array}$ & $\begin{array}{c}\text { Rank of } \\
D_{i}\end{array}$ & $\begin{array}{l}\text { Signed } \\
\text { Rank R } 1\end{array}$ & $\begin{array}{c}\text { Signed } \\
\text { normal } \\
\text { score } A_{1}\end{array}$ \\
\hline 1 & 59 & 34 & -25 & 7 & -7 & 0.1818 \\
\hline 2 & 57 & 33 & -24 & 6 & -6 & 0.2272 \\
\hline 3 & 54 & 32 & -22 & 4 & -4 & 0.3181 \\
\hline 4 & 57 & 36 & -21 & 3 & -3 & 0.3636 \\
\hline 5 & 61 & 36 & -23 & 5 & -5 & 0.2727 \\
\hline 6 & 56 & 36 & -20 & 2 & -2 & 0.4091 \\
\hline 7 & 53 & 26 & -27 & 9 & -9 & 0.0909 \\
\hline 8 & 56 & 28 & -28 & 10 & -10 & 0.0455 \\
\hline 9 & 52 & 35 & -17 & 1 & -1 & 0.4545 \\
\hline \multirow[t]{2}{*}{10} & 63 & 37 & -26 & 8 & -8 & 0.1363 \\
\hline & & & & & $\sum=$ & 2.49975 \\
\hline
\end{tabular}

Table 2: Analysis of wheelchair and monocoque postural angles

\begin{tabular}{ccccccc}
\hline S/N & $\begin{array}{c}\text { Postural angles on the } \\
\text { wheelchair(degrees) }\end{array}$ & $\begin{array}{c}\text { Postural angles on the } \\
\text { monocoque(degrees) }\end{array}$ & $\begin{array}{c}\text { Difference } \\
\mathrm{D}_{\mathrm{i}}\end{array}$ & $\begin{array}{c}\text { Rank } \\
\text { of } \mathrm{D}_{\mathrm{i}}\end{array}$ & $\begin{array}{c}\text { Signed } \\
\text { Rank } \mathrm{R}_{1}\end{array}$ & $\begin{array}{c}\text { Signed } \\
\text { normal } \\
\text { score } \mathrm{A}_{1}\end{array}$ \\
\hline 1 & 48 & 87 & +39 & 7 & +7 & 0.8888 \\
2 & 45 & 89 & +44 & 8 & +8 & 0.944 \\
3 & 60 & 90 & +30 & 5 & +5 & 0.778 \\
4 & 64 & 88 & +24 & 3 & +3 & 0.667 \\
5 & 68 & 79 & +11 & 1 & +1 & 0.555 \\
6 & 59 & 84 & +25 & 4 & +4 & 0.7222 \\
7 & 63 & 86 & +23 & 2 & +2 & 0.6111 \\
8 & 49 & 83 & +34 & 6 & +6 & 0.8333 \\
& & $\sum=$ & & & & 5.9993 \\
\hline
\end{tabular}

Table 3: Time taken to complete 100 metres

\begin{tabular}{|c|c|c|c|c|c|c|}
\hline $\mathrm{S} / \mathrm{N}$ & $\begin{array}{c}\text { Conventional } \\
\text { wheelchair type(Time } \\
\text { taken in sec) }\end{array}$ & $\begin{array}{l}\text { Monocoque (Time taken } \\
\text { in sec) }\end{array}$ & Difference $\mathrm{D}_{\mathrm{i}}$ & $\begin{array}{c}\text { Rank of } \\
D_{i}\end{array}$ & $\begin{array}{l}\text { Signed } \\
\text { Rank R1 }\end{array}$ & $\begin{array}{c}\text { Signed } \\
\text { normal } \\
\text { score } A_{1}\end{array}$ \\
\hline 1 & 49.24 & 8.54 & -40.70 & 8 & +8 & 0.8636 \\
\hline 2 & 48.56 & 9.62 & -38.94 & 6 & +6 & 0.7727 \\
\hline 3 & 39.34 & 8.46 & -30.88 & 2 & +2 & 0.5909 \\
\hline 4 & 36.84 & 7.28 & -29.56 & 1 & +1 & 0.5454 \\
\hline 5 & 48.52 & 7.34 & -41.18 & 9 & +9 & 0.9090 \\
\hline 6 & 45.01 & 6.55 & -38.46 & 4 & +4 & 0.6818 \\
\hline 7 & 48.24 & 6.42 & -41.82 & 10 & +10 & 0.9545 \\
\hline 8 & 46.08 & 7.56 & -38.52 & 5 & +5 & 0.7272 \\
\hline 9 & 47.38 & 8.23 & -39.15 & 7 & +7 & 0.8181 \\
\hline \multirow[t]{2}{*}{10} & 39.55 & 8.50 & -31.05 & 3 & +3 & 0.6363 \\
\hline & & $\sum=$ & & & & 7.4986 \\
\hline
\end{tabular}


Table 4: Time taken to complete 100 metres (Wilcoxon Signed Rank Test).

\begin{tabular}{|c|c|c|c|c|c|c|}
\hline $\mathrm{S} / \mathrm{N}$ & $\begin{array}{l}\text { Conventional wheelchair } \\
\text { type(Time taken in sec)X }\end{array}$ & $\begin{array}{l}\text { Monocoque(Time taken } \\
\text { in sec) Y }\end{array}$ & $\begin{array}{c}\text { Difference } D_{i} \\
(X-Y)\end{array}$ & $\begin{array}{c}\text { Rank of } \\
\text { Difference } \mathrm{R}_{\mathrm{i}}\end{array}$ & $\begin{array}{r}\text { Indicator } \\
\text { variable }{ }_{1}\end{array}$ & $\mathrm{R}_{\mathrm{i}}^{\varphi_{1}}$ \\
\hline 1 & 49.24 & 8.54 & +40.70 & 8 & 1 & 8 \\
\hline 2 & 48.56 & 9.62 & +38.94 & 6 & 1 & 6 \\
\hline 3 & 39.34 & 8.46 & +30.88 & 2 & 1 & 2 \\
\hline 4 & 36.84 & 7.28 & +29.56 & 1 & 1 & 1 \\
\hline 5 & 48.52 & 7.34 & +41.18 & 9 & 1 & 9 \\
\hline 6 & 45.01 & 6.55 & +38.46 & 4 & 1 & 4 \\
\hline 7 & 48.24 & 6.42 & +41.82 & 10 & 1 & 10 \\
\hline 8 & 46.08 & 7.56 & +38.52 & 5 & 1 & 5 \\
\hline 9 & 47.38 & 8.23 & +39.15 & 7 & 1 & 7 \\
\hline \multirow[t]{2}{*}{10} & 39.55 & 8.50 & +31.05 & 3 & 1 & 3 \\
\hline & \multicolumn{5}{|c|}{$\sum=$} & 55 \\
\hline
\end{tabular}

If the unstandardized test statistic is $\mathrm{T}$, then $\mathrm{T}_{1}=\mathrm{T}_{2}=55$

To find $\mathrm{Z}$, (the standardized test statistic), we need to determine the mean and standard deviation of T. Note that $n_{1}=n_{2}=10$

Recall that:

$$
E(T)=\frac{n_{1}\left(n_{1}+n_{2}+1\right)}{2}=\frac{10(10+10+1)}{2}=105
$$

Similarly, the standard deviation is obtained using the following relations

$$
\delta_{T}=\sqrt{\frac{n_{1} \times n_{2}\left(n_{1}+n_{2}+1\right)}{12}}=38.20
$$

The standardised test statistic:

$$
\mathrm{Z}=\frac{T-E(T)}{\delta_{T}}=\frac{55-105}{38.20}=1.3090
$$

Therefore, $\mathrm{P}$-value $=2 \mathrm{P}(\mathrm{Z}<-1.3090)$

$$
\begin{aligned}
& 2 \mathrm{P}=0.0952 \\
& \ldots \mathrm{P}(.5-\mathrm{x})=0.0475
\end{aligned}
$$

Hence, $\mathrm{P}$ - Value $=2 \mathrm{P}(\mathrm{Z}<-1.3090)=(.5-0.45245)$ $=0.04755$

The $T^{+}$, sum of positive $\operatorname{rank} \sum_{i=1}^{n=10} R_{1} \varphi_{1}=55$, the indicator variable $\varphi_{1}$ is uniform due to

the presence of a non negative values in the difference column. $\mathrm{T}$ is the Sum of the negative ranks $=0$. Since $\mathrm{n}$ $=10$, and the sum of positive ranks being 28 , we find from Wilcoxon signed rank $\mathrm{T}^{+}$, statistic table that the smallest significance level at which these data reject $H_{0}: \theta=0$. This situation favours the acceptance of $H_{1}$ which shows that there exists a significant difference between the conventional wheelchairs in use and the developed monocoque. This is further confirmed by the negative value of $Z=-1.3090$.

Again, the values obtained from these findings were computed and compared with values obtained from the conventional motorised wheelchair under the same condition. These values were subjected to statistical analysis using the Van der Waerden normal score test. The result of the test showed a remarkable significant difference between the developed mobility aid and the conventional type available to paraplegics in Nigeria.

Summarily, the implications are far reaching. It is a sure confirmation that the developed mobility aid readily meets the requirements of the target population. Surely, when scaled up from its pilot status, the utility will become palpable.

\section{CONCLUSIONS}

In conclusion therefore, a cost effective mobility aid that is appropriate to the needs of the disabled, suit their anthropometric requirements, low in fuel consumption rate and user friendly with regards to various operating conditions has been developed in our previous works and identified in this present article. It is therefore important for governments, non - governmental organisations, churches and public spirited individuals to provide this mobility aid for the disabled in our society for this is a precondition to lead a normal way of life and also enjoy equal opportunities and rights as ascribed to the perceived normal persons.

\section{REFERENCES}

[1] Odufuwa Olufemi, Towards Sustainable Public Transport for Disabled People in Nigerian Cities Stud. Home comm.. Sci. Vol. 192, 2007, pp 993 101.

[2] Seeger A. S., Strait, J. I. and Drury, C. Load on the upper Extremity in manual Wheel propulsion of subjects, Scand J Rehab. Med Sci. Sports Vol. 10, 1994, pp 261 - 290.

[3] Strait, R. E. Stone, J. and Savill. A Survey of Occupied Wheelchairs to determine their Overall 
Dimensions and Weight, 2000, Department of the environment, transport and Regions, London.

[4] Paquet, V. and Feathers, D. Anthropometric Study of Manual and Powered Wheelchair Users, International Journal of Industrial Ergonomics Vol. 33, 3, 2004, pp191 - 204.

[5] Mclaurin, J. C. Working conditions with different types of Disability, 1986. Ergonomics, Vol.18, No 5, pp $699-777$.

[6] Hamzart T. K. and Dada 0. 0. Wheelchair Accessibility of public Buildings in Ibadan, Nigeria,. Asia Pacific Disability Rehabilitation JournalVol.16, No 2, 2005, pp115 - 124.

[7] Babbie, E. The Practice of Social Research, 1998, Wadsworth, California.

[8] Fowler, M. Ouslander, J. and Papper, J. Managing Incontinences in Nursing Home Population, Journal of Enterostomalther, vol. 17,1990 pp 177 - 186.

[9] Canale, I. Felici, F. Marchetti, M. and Ricci, B. Ramp Length / Grade prescription for Wheelchair Dependent Individual, 1991. Paraplegia, Vol. 29 (7) pp $479-485$.

[10] United Nations, The standard rules on the Equalization of Opportunities for Persons with Disabilities, 1993. United Nations Report.

[11] Jaeger, Paul T. "Assessing Section 508 Compliance on Federal e-Government Web sites: A multimethod, user-Centered Evaluation of Accessibility for Persons with Disabilities." Government Information Quarterly Vol.23, No 2, 2006: pp169190.

[12] Clarke, Philippa, Jennifer A. Ailshire, and Paula Lantz. "Urban built environments and trajectories of mobility disability: findings from a national sample of community-dwelling American adults (1986-2001)." Social science \& medicine Vol. 69No 6, 2009, pp 964-970.

[13] Ahmed, Abubakar, Mahmoud Awad, Zakaria AlCheikh, and Mastura Adams "Disabling Campuses: The Development and Outcomes of Nigerian Disability Policies" OIDA International Journal of
Sustainable Development Vol. 7, No.10, 2014:pp 73-84.

[14] Danso, A. K., J. Ayarkwa, and Ayirebi Dansoh "State of Accessibility for the Disabled in Selected Monumental Public Buildings in Accra, Ghana" 2011.

[15] Papagiannakis, Apostolos, and Maria Tsami. "Enhance Accessibility in Traditional Districts a Case Study of the "Upper Town" of Thessaloniki." Procedia-Social and Behavioral Sciences 48, 2012: pp 3317-3327.

[16] Hwangbo, Hwan, Kim J, Kim S and Ji, Y. G. "Toward Universal Design in Public Transportation Systems: An Analysis of Low-Floor Bus Passenger Behavior with Video Observations." Human Factors and Ergonomics in Manufacturing \& Service Industries 2012.

[17] Rosenberg, Dori E.. "Outdoor built environment barriers and facilitators to activity among midlife and older adults with mobility disabilities." The Gerontologist 2012: gns119.

[18] Preston, John, and Fiona Rajé. "Accessibility, mobility and transport-related social exclusion "Journal of Transport Geography Vol.15 No3, 2007: pp151-160.

[19] Casas, Irene. "Social exclusion and the disabled: An accessibility approach" The Professional Geographer Vol. 59 No 4, 2007: pp 463-477.

[20] Alsnih, Rahaf, and David A. Hensher. "The mobility and accessibility expectations of seniors in an aging population" Transportation Research Part A: Policy and Practice 37.10, 2003: pp 903916.

[21] Ashiedu, F. and Igboanugo A. C. Measurements and Evaluation of Anthropometric Data of Nigerian adult Paraplegics for Wheelchair Design, Journal of Emerging Trend in Engineering and Applied Sciences (JETEAS) Vol. 4, No. 2,2013, pp 133-137.

[22] Igboanugo, A.C; Ashiedu, Fand Onifade M.K. Modelling Work Task and the Bending Capabilities of Subjects. Journal of the Nigerian Association of Mathematical Physics, Vol. 21, 2012, pp 261 - 270, 